Short Note

\title{
A simple modification to the EDAS method for two exceptional
} cases

\author{
Mehdi Keshavarz-Ghorabaee
}

Department of Management, Faculty of Humanities (Azadshahr Branch), Gonbad Kavous University, 49717-99151 Gonbad Kavous, Iran; m.keshavarz@gonbad.ac.ir

\begin{abstract}
Multi-criteria decision-making (MCDM) methods and techniques have been applied to many real-world problems in different fields of engineering science and technology. The evaluation based on distance from average solution (EDAS) method is a new and efficient MCDM method. The aim of this study is to propose a modification to address two exceptional cases in which the EDAS method fails to solve an MCDM problem.
\end{abstract}

Keywords: multi-criteria decision-making; MCDM; MADM; EDAS method

\section{Introduction}

In decision-making problems, we are usually confronted with some alternatives which need to be evaluated with respect to multiple criteria. Multi-criteria decision-making (MCDM) methods and techniques are very useful to handle such problems $[1,2]$. Many MCDM methods and techniques have been proposed by researchers during the past decades such as analytic hierarchy process (AHP), analytic network process (ANP), complex proportional assessment (COPRAS), data envelopment analysis (DEA), ELECTRE (stands for: ELimination Et Choix Traduisant la REalité), multi-objective optimization by ratio analysis (MOORA), preference ranking organization method for enrichment of evaluations (PROMETHEE), technique for order of preference by similarity to ideal solution (TOPSIS) and VIKOR (stands for: VlseKriterijumska Optimizacija I Kompromisno Resenje). Interested readers are referred to some recent review paper in this field [3-8].

The EDAS method is a new and efficient method proposed by Keshavarz Ghorabaee, et al. [9]. The process of evaluation in this method is based on positive and negative distances from an average solution. An alternative which has higher values of positive distances and lower values of negative distances from the average solution is a more desirable alternative according this method. This method has been extended to deal with MCDM problems under uncertainty [10-15]. Also it has been applied to some real-world problems [16-25].

In this study, a modification is made to the EDAS method to improve its efficiency for handling MCDM problems. First, two exceptional cases in which the EDAS method fails to give a correct solution are considered, and then it is shown that the modification enables the EDAS method to give a correct solution. In Section 2, the steps of the EDAS method are presented. Then two exceptional cases are explained in Section 3. A modification is proposed in Section 4, and the results are analyzed in this section. Finally conclusions are discussed in Section 4.

\section{The EDAS method}

Suppose that we have $n$ alternatives $\left(\mathcal{A}_{1}\right.$ to $\left.\mathcal{A}_{n}\right)$ and $m$ criteria $\left(\mathcal{C}_{1}\right.$ to $\left.\mathcal{C}_{m}\right)$, and the weight of each criterion $\left(w_{j}, j \in\{1,2, \ldots, m\}\right)$ is known. The steps of the EDAS method for evaluation of the alternatives with respect to the criteria are as follows: 
Step 1. Construction of decision-matrix:

$$
X=\left[\begin{array}{cccccc}
x_{11} & x_{12} & \ldots & x_{1 j} & \ldots & x_{1 m} \\
x_{21} & x_{22} & \ldots & x_{2 j} & \ldots & x_{2 m} \\
\vdots & \vdots & \ddots & \vdots & \ddots & \vdots \\
x_{i 1} & x_{i 2} & \cdots & x_{i j} & \cdots & x_{i m} \\
\vdots & \vdots & \ddots & \vdots & \ddots & \vdots \\
x_{n 1} & x_{n 2} & \cdots & x_{n j} & \cdots & x_{n m}
\end{array}\right]
$$

Step 2. Calculation of the elements of average solution $\left(g_{j}\right)$ :

$\mathcal{g}_{j}=\frac{\sum_{i=1}^{n} x_{i j}}{n}$

Step 3. Determination of the positive $\left(\mathcal{P}_{i j}^{d}\right)$ and negative $\left(\mathcal{N}_{i j}^{d}\right)$ distances:

$$
\begin{gathered}
\mathcal{P}_{i j}^{d}= \begin{cases}\frac{\max \left(0, x_{i j}-g_{j}\right)}{g_{j}} & \text { if } j \in B \\
\frac{\max \left(0, g_{j}-x_{i j}\right)}{g_{j}} & \text { if } j \in C\end{cases} \\
\mathcal{N}_{i j}^{d}= \begin{cases}\frac{\max \left(0, g_{j}-x_{i j}\right)}{g_{j}} & \text { if } j \in B \\
\frac{\max \left(0, x_{i j}-g_{j}\right)}{g_{j}} & \text { if } j \in C\end{cases}
\end{gathered}
$$

where $B$ and $C$ are the sets of benefit and cost criteria, respectively.

Step 4. Computation of the weighted summation of the distances:

$\mathcal{P}_{i}^{w}=\sum_{j=1}^{m} w_{j} \mathcal{P}_{i j}^{d}$

$\mathcal{N}_{i}^{w}=\sum_{j=1}^{m} w_{j} \mathcal{N}_{i j}^{d}$

Step 5. Normalization of the values of the weighted summations:

$$
\begin{aligned}
& \mathcal{P}_{i}^{n}=\frac{\mathcal{P}_{i}^{w}}{\max _{k} \mathcal{P}_{k}^{w}} \\
& \mathcal{N}_{i}^{n}=1-\frac{\mathcal{N}_{i}^{w}}{\max _{k} \mathcal{N}_{k}^{w}}
\end{aligned}
$$

Step 6. Calculation of the appraisal score of each alternative:

$$
\mathcal{S}_{i}=\frac{1}{2}\left(\mathcal{P}_{i}^{n}+\mathcal{N}_{i}^{n}\right)
$$

Step 7. Rank the alternatives according to decreasing values of $\mathcal{S}_{i}$.

\section{Exceptional cases}

In this section, two exceptional cases are described using two examples. In these cases the EDAS method is not capable of giving a correct solution.

3.1. Negative elements in the average solution

If the elements of the average solution have negative values, the EDAS method can result in incorrect solution or no solution.

- $\quad$ Example A: 
Suppose that we have a problem with two alternatives $\left(\mathcal{A}_{1}\right.$ and $\left.\mathcal{A}_{2}\right)$ and two criteria $\left(\mathcal{C}_{1} \in B\right.$ and $\left.\mathcal{C}_{2} \in C\right)$ with the following decision matrix.

$X=\left[\begin{array}{ll}-1 & -4 \\ -3 & -2\end{array}\right]$

According to this decision matrix and the type of the criteria, it's obvious that $\mathcal{A}_{1}>\mathcal{A}_{2}$. However, if we use the EDAS method, the elements of the average solution is $g_{1}=-2$ and $g_{2}=-3$, and the positive and negative distances are as follows:

$\mathcal{P}_{11}^{d}=\frac{\max (0,-1-(-2))}{-2}=-\frac{1}{2}$

$\mathcal{P}_{12}^{d}=\frac{\max (0,-3-(-4))}{-3}=-\frac{1}{3}$

$\mathcal{P}_{21}^{d}=\frac{\max (0,-3-(-2))}{-2}=0$

$\mathcal{P}_{22}^{d}=\frac{\max (0,-3-(-2))}{-3}=0$

$\mathcal{N}_{11}^{d}=\frac{\max (0,-2-(-1))}{-2}=0$

$\mathcal{N}_{12}^{d}=\frac{\max (0,-4-(-3))}{-3}=0$

$\mathcal{N}_{21}^{d}=\frac{\max (0,-2-(-3))}{-2}=-\frac{1}{2}$

$\mathcal{N}_{22}^{d}=\frac{\max (0,-2-(-3))}{-3}=-\frac{1}{3}$

According to the decision matrix, $\mathcal{A}_{1}$ has better values than $\mathcal{A}_{2}$ on $\mathcal{C}_{1}$, but as can be seen, the value of $\mathcal{P}_{11}^{d}$ is lower than $\mathcal{P}_{21}^{d}$. These values can result in wrong evaluation of alternatives. We can see the same problem in the other values of positive and negative distances. Moreover, if all of the elements of the average solution have negative values, $\max _{k} \mathcal{P}_{k}^{w}$ and $\max _{k} \mathcal{N}_{k}^{w}$ equals zero, and we cannot calculate the values of $\mathcal{P}_{i}^{n}, \mathcal{N}_{i}^{n}$ and $\mathcal{S}_{i}$.

\subsection{Zero elements in the average solution}

If some elements of the average solution are equal to zero, we cannot calculate some positive and negative distances. Therefore, the EDAS method cannot give a solution.

- Example B:

Suppose that we have three alternatives and two criteria with the following decision-matrix.

$X=\left[\begin{array}{cc}4 & 2 \\ 1 & 5 \\ -5 & 2\end{array}\right]$

In this example, it's not possible to calculate the values of $\mathcal{P}_{11}^{d}, \mathcal{P}_{21}^{d}, \mathcal{P}_{31}^{d}, \mathcal{N}_{11}^{d}, \mathcal{N}_{21}^{d}$ and $\mathcal{N}_{31}^{d}$ because the value of $g_{1}$ equals zero.

\section{A simple modification to the EDAS method}

We can see that the problems in the considered exceptional cases are definitely due to existing negative values in the decision matrix. For this reason, a modification is made to the EDAS method to eliminate this flaw from the evaluation process. A new step is added after the first step of the method as follows:

Step 1B. Transformation of the decision matrix. 
$X^{\prime}=\left[\begin{array}{cccccc}x^{\prime}{ }_{11} & x^{\prime}{ }_{12} & \ldots & x^{\prime}{ }_{1 j} & \ldots & x^{\prime}{ }_{1 m} \\ x^{\prime}{ }_{21} & x^{\prime}{ }_{22} & \ldots & x^{\prime}{ }_{2 j} & \ldots & x^{\prime}{ }_{2 m} \\ \vdots & \vdots & \ddots & \vdots & \ddots & \vdots \\ x^{\prime} & x^{\prime}{ }_{i 2} & \cdots & x^{\prime}{ }_{i j} & \cdots & x^{\prime}{ }_{i m} \\ \vdots & \vdots & \ddots & \vdots & \ddots & \vdots \\ x^{\prime}{ }_{n 1} & x^{\prime}{ }_{n 2} & \cdots & x_{n j}^{\prime} & \cdots & x^{\prime}{ }_{n m}\end{array}\right]$

where,

$x_{i j}^{\prime}=x_{i j}-\min _{j} x_{i j}$

Then the values of $x_{i j}^{\prime}$ are used in the next steps.

In Example $A$, if we use this step, the transformed decision matrix will be:

$X^{\prime}=\left[\begin{array}{ll}2 & 0 \\ 0 & 2\end{array}\right]$

Therefore, the elements of the average solution will be changed to $g_{1}=1$ and $g_{2}=1$. According to Eqs. (3) and (4) we can obtain rational values for the positive and negative distances.

$\mathcal{P}_{11}^{d}=\frac{\max (0,2-1)}{1}=1$

$\mathcal{P}_{12}^{d}=\frac{\max (0,1-0)}{1}=1$

$\mathcal{P}_{21}^{d}=\frac{\max (0,0-1)}{1}=0$

$\mathcal{P}_{22}^{d}=\frac{\max (0,1-2)}{1}=0$

$\mathcal{N}_{11}^{d}=\frac{\max (0,1-2)}{1}=0$

$\mathcal{N}_{12}^{d}=\frac{\max (0,0-1)}{1}=0$

$\mathcal{N}_{21}^{d}=\frac{\max (0,1-0)}{1}=1$

$\mathcal{N}_{22}^{d}=\frac{\max (0,2-1)}{1}=1$

For instance, we can see that $\mathcal{P}_{11}^{d}$, which was lower than $\mathcal{P}_{21}^{d}$ before this transformation, has a greater value than $\mathcal{P}_{21}^{d}$. Also the final appraisal scores after this transformation are $\mathcal{S}_{1}=1$ and $\mathcal{S}_{2}=0$ which confirm that $\mathcal{A}_{1}>\mathcal{A}_{2}$.

Moreover, in Example B, using this modification leads to following transformed decision matrix:

$X^{\prime}=\left[\begin{array}{ll}9 & 0 \\ 6 & 3 \\ 0 & 0\end{array}\right]$

According to Eq. (2), the average solutions are $g_{1}=5$ and $g_{2}=1$. As it can be seen, there is no element in the average solution which equals zero. Therefore, the other steps of the EDAS method can be made without any problem.

\section{Conclusions}

In this study, two exceptional cases which cause some problems in the process of the EDAS method have been addressed. The main issue was related to existing negative 
values in the decision matrix which could lead to negative or zero elements in the average solution. A modification by adding a new step has been made to the EDAS method. In this modification, the values of the decision matrix are transformed into positive values. It has been shown that the EDAS method is improved by this modification in the considered exceptional cases.

\section{References}

1. Abdel-malak, F.F.; Issa, U.H.; Miky, Y.H.; Osman, E.A. Applying decision-making techniques to Civil Engineering Projects. Beni-Suef University Journal of Basic and Applied Sciences 2017, 6, 326-331.

2. Gul, M.; Celik, E.; Gumus, A.T.; Guneri, A.F. A fuzzy logic based PROMETHEE method for material selection problems. Beni-Suef University Journal of Basic and Applied Sciences 2017.

3. Mardani, A.; Jusoh, A.; Md Nor, K.; Khalifah, Z.; Zakwan, N.; Valipour, A. Multiple criteria decision-making techniques and their applications - a review of the literature from 2000 to 2014. Economic Research-Ekonomska Istraživanja 2015, $28,516-571$.

4. Mardani, A.; Jusoh, A.; Zavadskas, E.K.; Kazemilari, M.; Ungku, N.U.A.; Khalifah, Z. Application of Multiple Criteria Decision Making Techniques in Tourism and Hospitality Industry: a Systematic Review. Transformations in Business E Economics 2016, $15,192-213$.

5. Mardani, A.; Jusoh, A.; Zavadskas, E.K.; Khalifah, Z.; Nor, K.M.D. Application of multiple-criteria decision-making techniques and approaches to evaluating of service quality: a systematic review of the literature. Journal of Business Economics and Management 2015, 16, 1034-1068.

6. Mardani, A.; Zavadskas, E.; Govindan, K.; Amat Senin, A.; Jusoh, A. VIKOR Technique: A Systematic Review of the State of the Art Literature on Methodologies and Applications. Sustainability 2016, 8, 37.

7. Zavadskas, E.K.; Mardani, A.; Turskis, Z.; Jusoh, A.; Nor, K.M. Development of TOPSIS method to solve complicated decision-making problems: An overview on developments from 2000 to 2015. International Journal of Information Technology E Decision Making 2016, 15, 645-682.

8. Keshavarz Ghorabaee, M.; Amiri, M.; Zavadskas, E.K.; Antucheviciene, J. Supplier evaluation and selection in fuzzy environments: a review of MADM approaches. Economic Research-Ekonomska Istraživanja 2017, 30, 1073-1118.

9. Keshavarz Ghorabaee, M.; Zavadskas, E.K.; Olfat, L.; Turskis, Z. Multi-criteria inventory classification using a new method of evaluation based on distance from average solution (EDAS). Informatica 2015, 26, 435-451.

10. Kahraman, C.; Keshavarz Ghorabaee, M.; Zavadskas, E.K.; Cevik Onar, S.; Yazdani, M.; Oztaysi, B. Intuitionistic fuzzy EDAS method: an application to solid waste disposal site selection. Journal of Environmental Engineering and Landscape Management 2017, 25, 1-12.

11. Keshavarz Ghorabaee, M.; Amiri, M.; Zavadskas, E.K.; Turskis, Z. Multi-criteria group decision-making using an extended EDAS method with interval type-2 fuzzy sets. E \& M Ekonomie a Management 2017, 20, 48-68.

12. Keshavarz Ghorabaee, M.; Zavadskas, E.K.; Amiri, M.; Turskis, Z. Extended EDAS Method for Fuzzy Multi-criteria Decision-making: An Application to Supplier Selection. International Journal of Computers Communications E Control 2016, 11, 358-371.

13. Stanujkic, D.; Zavadskas, E.K.; Keshavarz Ghorabaee, M.; Turskis, Z. An extension of the EDAS method based on the use of interval grey numbers. Studies in Informatics and Control 2017, 26, 5-12.

14. Peng, X.; Dai, J.; Yuan, H. Interval-valued Fuzzy Soft Decision Making Methods Based on MABAC, Similarity Measure and EDAS. Fundamenta Informaticae 2017, 152, 373-396.

15. Peng, X.; Liu, C. Algorithms for neutrosophic soft decision making based on EDAS, new similarity measure and level soft set. Journal of Intelligent $\mathcal{E}$ Fuzzy Systems 2017, 32, 955-968.

16. Ecer, F. Third-party logistics (3PLs) provider selection via Fuzzy AHP and EDAS integrated model. Technological and Economic Development of Economy 2018, 24, 615-634.

17. Keshavarz Ghorabaee, M.; Amiri, M.; Zavadskas, E.K.; Turskis, Z.; Antucheviciene, J. A new hybrid simulation-based assignment approach for evaluating airlines with multiple service quality criteria. Journal of Air Transport Management 2017, 63, $45-60$.

18. Keshavarz Ghorabaee, M.; Amiri, M.; Olfat, L.; Khatami Firouzabadi, S.M.A. Designing a multi-product multi-period supply chain network with reverse logistics and multiple objectives under uncertainty. Technological and Economic Development of Economy 2017, 23, 520-548.

19. Turskis, Z.; Morkunaite, Z.; Kutut, V. A hybrid multiple criteria evaluation method of ranking of cultural heritage structures for renovation projects. International Journal of Strategic Property Management 2017, 21, 318-329.

20. Turskis, Z.; Juodagalvienè, B. A novel hybrid multi-criteria decision-making model to assess a stairs shape for dwelling houses. Journal of Civil Engineering and Management 2016, 22, 1078-1087.

21. Stević, Ž.; Vasiljević, M.; Vesković, S. Evaluation in logistics using combined AHP and EDAS method. In Proceedings of the XLIII International Symposium on Operational Research, Serbia 2016; pp. 309-313. 
22. Trinkūnienė, E.; Podvezko, V.; Zavadskas, E.K.; Jokšienè, I.; Vinogradova, I.; Trinkūnas, V. Evaluation of quality assurance in contractor contracts by multi-attribute decision-making methods. Economic Research-Ekonomska Istraživanja 2017, 30, $1152-1180$.

23. Zavadskas, E.K.; Cavallaro, F.; Podvezko, V.; Ubarte, I.; Kaklauskas, A. MCDM Assessment of a Healthy and Safe Built Environment According to Sustainable Development Principles: A Practical Neighborhood Approach in Vilnius. Sustainability 2017, 9, Article Number: 702.

24. Juodagalvienė, B.; Turskis, Z.; Šaparauskas, J.; Endriukaitytė, A. Integrated multi-criteria evaluation of house's plan shape based on the EDAS and SWARA methods. Engineering Structures and Technologies 2017, 9, 117-125.

25. Stević, Ž.; Pamučar, D.; Vasiljević, M.; Stojić, G.; Korica, S. Novel Integrated Multi-Criteria Model for Supplier Selection: Case Study Construction Company. Symmetry 2017, 9, 279. 